\title{
Historical Development of the Indigenous Yue Dialects in Hong Kong
}

\author{
Lau Chun Fat \\ Hong Kong Polytechnic University, Hong Kong, China
}

\begin{abstract}
The indigenous inhabitants of Hong Kong in broad sense speak up to eight different speeches, of which five belong to the Yue dialect group. In this paper we are investigating four speeches belonging to the Yue dialect group and their historical development. It is found that they diverged from Cantonese a few centuries ago and underwent several common changes in the rimes, and can be divided into two major groups, WTH (Weitouhua, 圍頭話) and DPH (Dapenghua, 大鵬話). The former experienced an a-raising, but the development of the MC (Middle Chinese) $\mathrm{C}$ tone is similar to that of Cantonese. The latter received influences from Hakka, containing three rimes typical of Hakka in some glosses, and the $\mathrm{C}$ tone is split like Hakka. The D tone is different in all four dialects, which points to the fact that $\mathrm{D}$ tone development is a recent event.
\end{abstract}

Keywords: Hong Kong indigenous inhabitants, Yue dialect, language endangerment, historical linguistics

\section{Introduction}

\section{Hong Kong Indigenous Inhabitants and Their Dialects}

Hong Kong is now a metropolitan with more than seven Million inhabitants. However, the overwhelming majority are immigrants in the past decades, mostly from Guangdong, and a significant amount from Fujian and Shanghai (Lau \& So, 2005). Little is known about the indigenous inhabitants and their dialects especially the Yue dialect part, since more books and papers always focused on Hakka (Lau, 2005).

According to the definition of the Hong Kong government, indigenous inhabitants are the people who built hundreds of villages in N.T. (New Territories) before 1898, thus excluding fisherman. However, this term is only valid for the rural area named the N.T. because of political reasons not to be discussed here.

The first permanent population of Hong Kong was the DENG (鄧) clan who settled in Kamtin around a millennium ago. Together with four other clans (WEN 文, PENG 彭, HOU 侯, and LIAO 廖) who came a bit later, these people occupied most of the plains and estuary areas of N.T.. They named themselves Punti (locals) and speak a variety of the Yue dialect called WTH (Weitouhua, 圍頭話), literally walled-village speech.

The second most spoken dialect among the indigenous inhabitants is Hakka, who came to Hong Kong around 1700-1800, occupying smaller valleys and narrow coastal plains. They built more villages than the Punti, but the population is slightly less than that of Punti. Punti and Hakka add together to represent more than $95 \%$ of the indigenous population.

Lau Chun Fat, doctor, Department of Chinese and Bilingual Studies, Hong Kong Polytechnic University. 
However, there are other smaller dialect groups in Hong Kong, such as the Pingzhou dialect in the Mirs Bay and the Tingjiao dialect, both are varieties of Yue; and the Pinpo dialect which is a variety of Hakka. The Danjia dialect of the fisherman population is also a variety of Yue, which sounds closest to HKC (Hong Kong Cantonese), but it is not counted as an indigenous dialect of Hong Kong for the reason named at the beginning. Together with the fisherman Hoklo dialect, there are at least seven different dialect varieties spoken before the arrival of the Englander.

\section{Yue Dialects in Hong Kong}

Today, the most often heard dialect in Hong Kong is Cantonese, which is regarded as the representative of the Yue dialect. Cantonese, like English, is not indigenous, but brought to Hong Kong since the establishment of the colony. It became the lingua franca of most Chinese since then, and is now the language used by most schools, government, and media. Originated as the speech of the Provincial center, Guangzhou, which was erroneously translated as "Canton" (a misnomer for the Province), Cantonese was also misnamed by the Hong Kong Government as "Punti" (local or indigenous), and later by the citizens as "Guangdonghua" (speech of Guangdong Province) (Lau \& So, 2005).

However, Cantonese is neither indigenous to Hong Kong nor the only speech in Guangdong. In eastern Guangdong, people use Hakka or Chouzhou dialects to communicate, which is totally unintelligible for any Yue dialect speaker. In Western Guangdong, Southern Guangxi, and also the Pearl River Delta around Hong Kong, there are hundreds of speeches that are similar, but are distinguishable from Cantonese, which are considered as Yue dialects in the scope of Chinese dialectology. According to our calculations, about 52\%-58\% of the population of Hong Kong stemmed from these Yue dialect speakers (So \& Lau, 2013). These dialects flourished in Hong Kong before 1980 and gradually dried out ass the older generations passed away. As most Hong Kong citizens under 65 are educated in Cantonese, Yue dialects other than Cantonese are regarded as uneducated, old-fashioned or even rude and impolite. As a result, even the WTH which is widely spoken in the N.T. was gradually abandoned by most young villagers and is highly endangered.

\section{IYDs (Indigenous Yue Dialects) in Hong Kong}

If we interpret the word "indigenous" in broad sense, we should also include the fishermen's dialect. But now the term "indigenous" applies only to people living on the land, who earn their living usually by farming for generations. In this paper, four varieties of IYD are documented to study the historical linguistics of Yue dialects in Hong Kong: WTH in Santin (新田圍頭話), WTH in Shekbik of Lantao (石壁圍頭話), TJH (Tingjiaohu, 汀角 話), and PZH (Pingzhouhua (平洲話). It is also found there are significant different among the WTH on Lantao Island and WTH in north district of Hong Kong. WTH has been documented by Sagart (1982), and by Zhan and Cheung (1987), but the data were not consistent. The data here are consistent with Sagart's findings.

$\mathrm{TJH}$ is a Yue dialect spoken by the indigenous villagers of Tingkok village near Tai Mei Tuk (大美篤) with more than 1,000 inhabitants. PZH was used by around 2,000 inhabitants of the Pingchau island on Mirs Bay until around 1980. Now the island is abandoned and becomes a tourist attraction, because the sedimentary rock landscape becomes the geographical park of Hong Kong, which is now listed as a "world natural heritage". Most villagers moved to Taipo and have given up their dialect as they assimilated into the city life. However, elder villagers are still using the speech in their usual conversations. 
The first two belong to WTH, and the last two belong to the DPH (Dapenghua, 大鵬話) group, which received more influence from Hakka.

\section{Phonology of the IYD in Hong Kong}

\section{Onsets}

The onsets of Hong Kong IYD are almost identical to that of HKC with only some slight modifications. HKC is analyzed to have 18 onsets, if we count $\mathrm{j}, \mathrm{w}, \mathrm{kw}, \mathrm{khw}$ as onsets, and $\mathrm{n} / \mathrm{l}$ is still not merged (Linguistic Society of Hong Kong, 1997) (see Table 1):

Table 1

Onsets of $H K C$

\begin{tabular}{|l|l|l|l|l|}
\hline $\mathrm{p}($ 巴) & $\mathrm{p}^{\mathrm{h}}$ (怕) & $\mathrm{m}$ (媽) & $\mathrm{f}$ (花) & \\
\hline $\mathrm{t}($ 打 $)$ & $\mathrm{t}^{\mathrm{h}}$ (他) & $\mathrm{n}$ (那) & & 1 (啦) \\
\hline $\mathrm{ts}$ (渣) & $\mathrm{ts}^{\mathrm{h}}$ (叉) & & $\mathrm{s}$ (沙) & \\
\hline $\mathrm{k}$ (家) & $\mathrm{k}^{\mathrm{h}}$ (卡) & $\mathrm{n}$ (牙) & $\mathrm{h}$ (哈) & $\mathrm{j}$ (也) \\
\hline $\mathrm{kw}($ 瓜 $)$ & $\mathrm{k}^{\mathrm{h}}$ (誇) & & & $\mathrm{w}$ (娃) \\
\hline
\end{tabular}

The differences in the onsets are summarized as following:

Santin WTH has almost exactly the same onsets, except some characters beginning with [h] (usually followed by o- in HKC) are [f], and able to distinguish $\mathrm{n} / \mathrm{l}$ clearly. In IYD, characters with [h] as onset changing to $f$ are due to the changes of rime (except in PZH): ho- $>$ hu- $>$ f-, e.g., 海 fui 35 . Among older speakers, n (二) also exists in some characters like ni (二 two), nit (熱 hot), which has [i] as main vowel. This is regarded as an allophone of $\eta$ which cannot has [i] as main vowel. Among younger speakers, the onset $\mathrm{n}$ is changed to $\mathrm{j}$, as in Cantonese.

(1) Shekbik WTH is very similar to Santin dialect, but it omits the "w" in kw, kwh, reducing the number of onsets to 16 .

(2) Both TJH and PZH are similar to the Shekbik WTH, but they do not distinguish $\mathrm{n} / \mathrm{l}$. Besides, they has less $\mathrm{h}$ changed to $\mathrm{f}$, and in the case of $\mathrm{PZH}, \mathrm{h}$ is not changed to $\mathrm{f}$ even before an $[\mathrm{u}]$. Besides, both have more aspirated onsets (see below).

(3) In PZH, the voiced onsets of MC (Middle Chinese) $\mathrm{C}$ tone (Departing tone, 去聲) are devoiced and aspirated with tone value of 55, which are different from HKC and WTH (unaspirated, 22). In TJH, there are considerable mixing of these devoicing, with commonly used characters pronounced as aspirated with 55, while the other has unaspirated with 22. We believe that it is a result of language contact with Cantonese or WTW.

\section{Rimes}

Unlike Cantonese, which has 53 rimes (when kw and kwh are regarded as onsets), the IYD of Hong Kong has less rimes because:

(1) The number of vowels is reduced to 10 in WTH (a, i, u, $\varepsilon, \supset, y, \propto, \mathfrak{x}, \mathrm{e}$, and o, without $\ominus, \mathrm{e})$; and seven in the case of the TJH and PZH (a, i, u, $\varepsilon$, , , e, and o).

Santin WTH has only four codas ( $m, \mathrm{y}, \mathrm{p}$, and $\mathrm{k}$ ).

(2) ji, ion/t merge into ui, un/t (un/k in Santin) 
(3) In the Tingkok and Pingchau dialect, three Hakka rimes (ia, iay, and iak) mix into the rime system, but still it is simpler than Cantonese.

Tables 2-4 list the rimes of these dialects:

Table 2

Rimes of Santin WTH (37) (Rimes in Italics Indicate That They Are Absent in HKC, Only the First Character Has the Same Pronunciation in Cantonese)

\begin{tabular}{|c|c|c|c|c|c|c|}
\hline a 家 & ai 階 & au 交 & am 監 & I & ap 夾 & I \\
\hline 1 & ei 鷄 & eu 狗高 & em 金 & ey 美京巾詢 & ep 急 & ek 北極吉率 \\
\hline i 思肌 & / & iu 嬌 & im 兼 & in 肩 & ip 劫 & it 切 \\
\hline 0 哥 & 1 & 1 & 1 & oy 江 & / & ok 各 \\
\hline 1 & I & I & / & ery 間耕 & 1 & cek 格殺 \\
\hline œ 靴 & $/$ & 1 & 1 & œ姜 & 1 & œk 脚 \\
\hline$\varepsilon$ 些 & 1 & 1 & 1 & Ey 鄭 & 1 & $\varepsilon \mathrm{k}$ 衹 \\
\hline u 夫布 & ui 杯該 & 1 & 1 & un 搬幹 & / & ut 闊割 \\
\hline 1 & 1 & / & 1 & on 公 & / & ok 局 \\
\hline $\mathrm{y}$ 書居 & & 1 & 1 & yn 淵 & 1 & yk 月 \\
\hline
\end{tabular}

Table 3

Rimes of Shekbik WTH (43) (Rimes in Italics Indicate That They Are Absent in HKC, the Second Character Has a Different Pronunciation in Cantonese)

\begin{tabular}{|c|c|c|c|c|c|c|c|c|}
\hline a 家 & ai 階 & au 交 & am 監 & 1 & 1 & ap 夾 & 1 & / \\
\hline 1 & 1 & I & / & aen 間 & aeg 耕 & / & cet 殺 & cek 格 \\
\hline 1 & ei 鷄 & eu 狗高 & em 金 & en 巾詢 & ey 美京 & ер 急 & et 吉率 & ek 北極 \\
\hline$i$ 思肌 & 1 & iu 嬌 & im 兼 & in 肩 & / & ip 劫 & it 切 & 1 \\
\hline 0 哥 & 1 & 1 & I & 1 & эๆ 江 & 1 & 1 & गk 各 \\
\hline œ 靴茄 & 1 & I & 1 & 1 & œ姜 & 1 & 1 & œk 脚 \\
\hline$\varepsilon$ 些 & I & 1 & 1 & I & Ey 鄭 & / & 1 & Ek 衹 \\
\hline $\mathrm{u}$ 夫布 & ui 杯該 & I & 1 & un 搬幹 & & 1 & ut 闊割 & \\
\hline 1 & 1 & I & I & I & On 公 & 1 & 1 & ok 局 \\
\hline $\mathrm{y}$ 書居 & & I & / & yn 淵 & 1 & / & yt 月 & I \\
\hline
\end{tabular}

Table 4

Rimes of Tingkok and Pingchau Dialect (43) (Rimes in Italics Indicate That They Are Absent in HKC, Only the First Character Has the Same Pronunciation in Cantonese)

\begin{tabular}{|c|c|c|c|c|c|c|c|c|}
\hline a 家 & ai 階 & au 交 & am 監 & an 間 & ang 耕 & ap 夾 & at 殺 & ak 格 \\
\hline & ei 鷄 & eu 狗高 & $\mathrm{em}$ 金 & en 巾言 & ey 美京 & ep 急 & et 吉率 & ek 北極 \\
\hline i 思肌書居 & 1 & iu 嬌 & im 兼 & in 肩 & / & ip 劫 & it 切月 & / \\
\hline ia 蛇 & 1 & f & f & / & ian 病 & 1 & / & iak 鵲 \\
\hline 0 哥 & 1 & I & / & 1 & эๆ 江 & 1 & 1 & ok 各 \\
\hline i 5 靴茄 & / & I & 1 & / & ion 姜 & / & 1 & ijk 脚 \\
\hline$\varepsilon$ 些 & / & / & / & / & $\varepsilon \eta$ 鄭 & / & / & $\varepsilon \mathrm{k}$ 衹 \\
\hline $\mathrm{u}$ 夫布 & ui 杯該 & / & / & un 搬幹 & on 公 & 1 & ut 闊割 & ok 局 \\
\hline
\end{tabular}

Despite the close similarity of the latter two, they are not speaking the same speech as there are more 
borrowings in the Tingkok dialect from Hakka and Cantonese.

\section{Tones}

The total number of tones is less than that of Cantonese which is shown in Table 5 (total means the number of tone value varieties):

Table 5

Comparison of Tones Among Different Yue Dialects

\begin{tabular}{lllllllllll}
\hline Tone $^{*}$ & 1 & 2 & 3 & 4 & 5 & 6 & 7 & 8 & 9 & Total \\
\hline HKC & 55 & 35 & 33 & 11 & 13 & 22 & 55 & 33 & 22 & 6 \\
STW & 13 & 35 & 13 & 11 & 13 & 22 & 35 & 35 & 22 & 4 \\
SBW & 13 & 35 & 13 & 11 & 13 & 22 & 55 & 55 & 22 & 5 \\
TJH & 13 & 35 & 33 & 11 & 13 & 22,55 & 55 & 55 & 22 & 5 \\
PZH & 33 & 35 & 33 & 11 & 13 & 55 & 55 & 55 & 55 & 5 \\
\hline
\end{tabular}

Note. ${ }^{*}$ The tone number according to traditional arrangement, with entering tones numbered as 7-9.

\section{Historical Linguistics}

\section{Historical Linguistics of the Onset and Rimes}

There are little changes in the onsets, but there are significant changes in the rimes.

The onsets of the PCH group are aspirated if they originated from the MC C and D tones. This is markedly different from Cantonese and WTH. However, significant amounts of non-aspiration occur in TJH, which may have been influence from Cantonese. $\supset$ - in Cantonese is changed to $\mathrm{u}$ - in all four dialects: e.g., 臺 th $\supset \mathrm{i}>$ thui, 肝 $\mathrm{k} \supset \mathrm{n}>\mathrm{kun}$, but $\supset$ without coda is not changed. Because of the rime change, syllable with [h] as onsets are changed to [f] in WTH, but are not changed in the other two DPH.

ey/ek in Cantonese is changed to ey/ek in all four dialects. $\Theta$ - does not exist in all four dialects, all $\Theta$ - are $\mathrm{e}$ - in the IYD. a- (with $\mathrm{n}, \mathrm{y}, \mathrm{t}$, and $\mathrm{k}$ as coda) is changed to $æ$ in the two WTH but not in the other two. Only WTH has $y, œ$. The other two change these to $\mathrm{i} / \mathrm{u}$, io. The Cantonese "ou" is " $\mathrm{e} u$ " in these dialects if they are from the MC Xiao Rime group. The other Cantonese "ou" is results of breaks from $[\mathrm{u}]$ and remains as $[\mathrm{u}]$ in the IYD. The Santin WTH does not have the codas $n$, t. They are changed to $\mathrm{y} / \mathrm{k}$. The Tingkok and Pingchau dialects have ia, iay/iak as rimes, which exist in loans from Hakka.

Cantonese underwent breaks in i, u, and y in the 20th century to ei, ou, $\theta$, and y; but this did not happen in these dialects.

\section{Tones}

HKC have six tones, but there are a lot of mergers in the indigenous dialects. Hong Kong IYD have four to five tones only. We can look at the changes in the MC tones. The A tone is all different from HKC, but the B tone is the same. The $\mathrm{C}$ tone is almost the same for HKC and WTH, but different for the other two which are the same as Hakka. The D tone is simpler in the indigenous dialects. They are different from both HKC and Hakka.

According to the tone differences, we can see that the Proto-Yue dialect, an offshoot from MC around the end of the SONG Dynasty (CA. 1200), devoicing occurred in the A and B tones in the same pattern. Devoicing of the $\mathrm{C}$ tone is different for the DPH group, which follows exactly what Hakka did (with a 55 tone and aspiration in the stops and affricates), but WTH devoiced the $\mathrm{C}$ tone just similar to Cantonese (with a 22 tone and not aspirated 
in the stops and affricates). We guess this to be around the Middle of the MING Dynasty around 1500, i.e., after the foundation of the Dapeng fortress in Shenzhen (Wang \& Weng, 1998).

Devoicing in the $\mathrm{D}$ tone is different for most dialects, which means that most of them are independent of each other. For Cantonese, devoicing of the $\mathrm{D}$ tone resulted in the formation of three different tones, 55 and 33 for the unvoiced which differentiated according to their main vowel, and a 22 for the devoiced. Both WTH dialects are similar in pattern but the unvoiced tone is not split. As a result, they have only two tones: The Santin dialect has a 35 tone for the unvoiced, while the Shekbik dialect has a 55, and the voiced are 22. The devoiced onset is also the same as in Cantonese with unaspirated onsets. For the DPH group, PZH has only one tone (55) for the entering tone, which is the simplest among Yue dialects. Interestingly, TJH behaves like SBW. We believe that TJH receives more Cantonese influence than PZH.

Speakers of TJH told us that their village was founded more than 400 years ago, that means they diverged from DPW around the end of the 16th Century, and came into contact with Cantonese shortly after. If devoicing of $\mathrm{C}$ tone occurred around 1500 which followed the Hakka pattern and the devoicing was not completed, some characters may be read as 22 after devoicing. Shortly afterwards, devoicing of D occurred, following the pattern of early.

\section{Conclusions}

To summarize, we found that the IYD in Hong Kong can be divided into two major groups, WTH and the DPH group. The former has more vowels and the D tone of MC is split into 13 and 22. The latter has less vowels because of the unrounding of $y$ and $\propto$ into $i$ and is, and the $D$ tone is split into $13 / 33$ and 55 . IYD diverged from Cantonese some centuries ago, sharing the innovations of [o-] raising, [e] in en/ek, and o in ou centralizing to [e]. WTH formed the innovations of a-raising to æ. In Santin WTH, -n/-t also changed recently to $-\mathrm{y} / \mathrm{-k}$, which is not shared by other IYD. In the DPH group, $\mathrm{y}$, and $œ$ are unrounded to i, is, and the rime ia, iay, and iak are borrowed from Hakka. They also behave similarly in the devoicing of the MC C tone.

On the other hand, sound changes also occurred in Cantonese. Cantonese vowels $i, u$, and $y$ at the end of the 19th century (Ball, 1888) underwent breaks in the 20th century to ei, ou, and $\ominus$ y (see Figure 1).

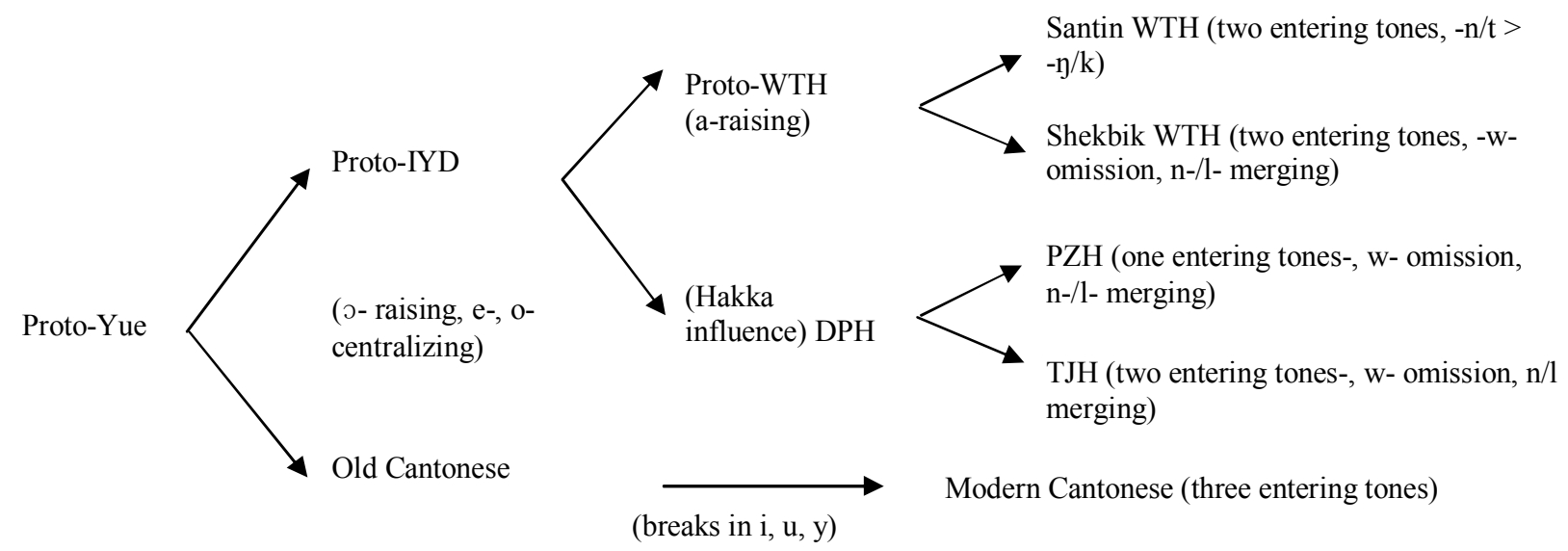

Figure 1. Historical development of Cantonese and the IYD in Hong Kong. 
The IYDs have simpler phonologies than HKC, as exemplified in the number of vowels, codas, rimes, and tones. IYDs are similar among themselves in their rimes, so that they share some important characteristics which are not found in HKC, especially in their rimes. Historically, the changes in the rime of əi, on, ot, ou to ui, un, ut, and eu were common to all IYDs. These changes also affect $\mathrm{h}$ to change to $\mathrm{f}$ in WTH. This means that the change of hu $>$ f occurred later than o- $>\mathrm{u}$ - in IYD. They did not develop the vowels $\theta$, e, and o as in HKC which all correspond to $\mathrm{e}$ in IYD. These dialects also did not share the A tone split in HKC. WTH subgroup shared B and C, PZH only B. PZH shared the tone C split with Hakka.

In the DPH subgroup, $\mathrm{n} / \mathrm{l}$ merged (and also HKC and HK Hakka). This is a recent sound change and involved both Yue and Hakka around HK. WTW and also the Hakka dialect in Meixian did not participate in this sound change.

Tone D split is different in all IYD, and also different from HKC and Hakka. It seems that they all split their $\mathrm{D}$ tone separately. This also suggests that this is a very recent sound change.

\section{References}

Ball, J. D. (1888). Cantonese made easy. Hong Kong: China Mail Office.

Lau, C. F. (2005). The indigenous dialect of Hong Kong: A vanishing voice (香港原居民客語: 一個消失中的聲音). Hong Kong: Language Society of Hong Kong.

Lau, C. F., \& So, D. W. C. (2005). From dialect coexistence to Cantonese-Dominant dialects—A preliminary study of language shift in the Hong Kong society during 1949-1971 (從方言雜處到廣府話爲主一1949-1971年間香港社會語言轉型的初步 探討). Journal of Chinese Sociolinguistics, 5, 89-104.

Linguistic Society of Hong Kong. (1997). Chinese character list by Cantonese transliteration (Jyutping). Hong Kong: Language Society of Hong Kong.

Sagart, L. (1982). Phonology of a Cantonese dialect of the new territories: Kat Hing Wai. Journal of the Hong Kong Branch of the Royal Asiatic Society, 22, 142-160.

So, D. W. C., \& Lau, C. F. (2013). Rapid large scale intra-nationality language shift in Hong Kong 1949-1971. Journal of Chinese Linguistics, 41(1), 21-51.

Wang, X., \& Weng, S. (Ed.). (1998). Dapeng Castle (大鹏所城). Shenzhen: Shenzhen Government Press.

Zhan, B., \& Cheung, Y. S. (1987). A survey of dialects in the Pearl River Delta, Volume 1: Comparative morpheme-syllabary (珠 江三角洲方言字音對照). Hong Kong: New Century Publisher. 